\title{
Article \\ Prevalence of COVID-19 Vaccine Side Effects among Healthcare Workers in the Czech Republic
}

\author{
Abanoub Riad ${ }^{1,2, *,+} \mathbb{D}$, Andrea Pokorná ${ }^{2,3,+}+\mathbb{D}$, Sameh Attia ${ }^{4}\left(\mathbb{D}\right.$, Jitka Klugarová 1,2 ${ }^{\text {, Michal Koščík }}{ }^{1,5, \ddagger}$ \\ and Miloslav Klugar $1,2, \ddagger$ (D)
}

1 Department of Public Health, Faculty of Medicine, Masaryk University, Kamenice 5, 62500 Brno, Czech Republic; klugarova@med.muni.cz (J.K.); koscik@med.muni.cz (M.K.); klugar@med.muni.cz (M.K.)

2 Czech National Centre for Evidence-Based Healthcare and Knowledge Translation (Cochrane Czech Republic, Czech EBHC: JBI Centre of Excellence, Masaryk University GRADE Centre), Institute of Biostatistics and Analyses, Faculty of Medicine, Masaryk University, Kamenice 5, 62500 Brno, Czech Republic; apokorna@med.muni.cz

3 Department of Nursing and Midwifery, Faculty of Medicine, Masaryk University, Kamenice 5, 62500 Brno, Czech Republic

4 Department of Oral and Maxillofacial Surgery, Justus-Liebig-University, Klinikstrasse 33, 35392 Giessen, Germany; sameh.attia@dentist.med.uni-giessen.de

5 Czech Clinical Research Infrastructure Network, Department of Pharmacology, Faculty of Medicine, Masaryk University, Kamenice 5, 62500 Brno, Czech Republic

* Correspondence: abanoub.riad@med.muni.cz; Tel.: +420-549-496-572

+ Equal contribution as first authorship.

$\ddagger$ Equal contribution as senior authorship.

check for updates

Citation: Riad, A.; Pokorná, A.; Attia, S.; Klugarová, J.; Koščík, M.; Klugar, M. Prevalence of COVID-19 Vaccine Side Effects among Healthcare Workers in the Czech Republic. J. Clin. Med. 2021, 10, 1428. https://doi.org/ $10.3390 /$ jcm 10071428

Academic Editor: Giovanni Gabutti

Received: 9 March 2021

Accepted: 23 March 2021

Published: 1 April 2021

Publisher's Note: MDPI stays neutral with regard to jurisdictional claims in published maps and institutional affiliations.

Copyright: (c) 2021 by the authors. Licensee MDPI, Basel, Switzerland. This article is an open access article distributed under the terms and conditions of the Creative Commons Attribution (CC BY) license (https:// creativecommons.org/licenses/by/ $4.0 /)$.
Abstract: Background: COVID-19 vaccine side effects have a fundamental role in public confidence in the vaccine and its uptake process. Thus far, the evidence on vaccine safety has exclusively been obtained from the manufacturer-sponsored studies; therefore, this study was designed to provide independent evidence on Pfizer-BioNTech COVID-19 vaccine side effects. Methods: A cross-sectional survey-based study was carried out between January and February 2021 to collect data on the side effects following the COVID-19 vaccine among healthcare workers in the Czech Republic. The study used a validated questionnaire with twenty-eight multiple-choice items covering the participants' demographic data, medical anamneses, COVID-19-related anamneses, general, oral, and skin-related side effects. Results: Injection site pain $(89.8 \%)$, fatigue $(62.2 \%)$, headache $(45.6 \%)$, muscle pain $(37.1 \%)$, and chills (33.9\%) were the most commonly reported side effects. All the general side effects were more prevalent among the $\leq 43$-year-old group, and their duration was mainly one day (45.1\%) or three days $(35.8 \%)$ following the vaccine. Antihistamines were the most common drugs associated with side effects, thus requiring further investigation. The people with two doses were generally associated with a higher frequency of side effects. Conclusions: The distribution of side effects among Czech healthcare workers was highly consistent with the manufacturer's data, especially in terms of their association with the younger age group and the second dose. The overall prevalence of some local and systemic side effects was higher than the manufacturer's report. Further independent studies on vaccine safety are strongly required to strengthen public confidence in the vaccine.

Keywords: adverse effects; BNT162 vaccine; cross-sectional studies; COVID-19; Czech Republic; drug-related side effects and adverse reactions; health personnel; mass vaccination; prevalence

\section{Introduction}

Vaccine hesitancy $(\mathrm{VH})$ refers to the "delay in acceptance or refusal of vaccines despite availability of vaccine services"; it is an emerging public health challenge nourished by misinformation related to vaccines effectiveness and safety [1-3]. In a recent nation-wide study, aversion to vaccines' potential side effects was the most frequent cause for $\mathrm{VH}$ 
among population groups in the United Kingdom (U.K.) [4]. This finding was supported in the context of COVID-19 vaccines, because a fear of side effects was the most prominent reason to decrease the readiness of healthcare workers and students in Poland to accept the vaccination [5,6]. Consequently, a systematic review of the strategies of tackling VH revealed that raising public awareness of vaccines' effectiveness and honesty regarding their side effects is vital for improving vaccine uptake [7]. The launch of the COVID-19 vaccine rollout in December 2020 was a landmark for overcoming this pandemic crisis; therefore, it had been recommended to split the pandemic history to pre-vaccination (B.V.; before vaccine) and post-vaccination (A.V.; after vaccine) eras. COVID-19-related literature should be defined in relation to this parameter either as B.V. or A.V. [8].

In a cross-sectional study of influenza vaccine side effects, three out of thirty-seven participants who were recently influenza-vaccinated $(8 \%)$ developed oral side effects, thus implying a non-statistically significant relationship between influenza vaccine and the oral cavity [9]. The short-term side effects of vaccines vary in their clinical presentation; however, they are commonly related to prophylactic vaccines' humoral immune response [10]. The oral cavity has been a locus for the adverse events of an array of vaccines, e.g., diphtheria, tetanus, acellular pertussis, and polio vaccines [9]. The COVID-19-related oral symptoms were attributed to the high expression of angiotensin-converting enzyme 2 (ACE2) receptors in the tongue's epithelial cells, buccal and gingival mucosa [11-18].

Thus far, all the available data on COVID-19 vaccine side effects has been published by manufacturer-funded studies which are in compliance with the drug authorities' guidelines and monitored by third-parties [19]. A lack of independent studies on vaccines' safety may adversely impact the vaccine uptake, which has to be accelerated in the next few months in order to escape this viscous circle of the virus and its variants [7]. Therefore, this study's primary objective was to estimate the prevalence of Pfizer-BioNTech COVID-19 vaccine side effects among the early vaccinated healthcare workers in the Czech Republic.

The secondary objectives were:

1. To identify the potential risk factors of Pfizer-BioNTech COVID-19 vaccine side effects;

2. To evaluate the correlation of general side effects, oral side effects, and skin-related side effects.

\section{Materials and Methods}

\subsection{Study Design}

This cross-sectional survey-based study was carried out from 27 January 2021 to 27 February 2021, to estimate the prevalence of COVID-19 vaccine side effects among the priority groups of the randomly selected healthcare workers in the Czech Republic. The study utilized a self-administered questionnaire of multiple-choice items which had been designed digitally using KoBoToolbox version 2.021.03 (Harvard Humanitarian Initiative. Cambridge, MA, USA, 2021).

The study protocol was registered in the trials registry of the U.S. National Library of Medicine (NLM) under the title "Oral Side Effects of COVID-19 Vaccine-OSECV" with the identifier NCT04706156; it was reported following the Strengthening the Reporting of Observational Studies in Epidemiology (STROBE) guidelines for cross-sectional studies [20,21].

After ethical clearance, invitation emails for the local coordinators of the member institutions in the Czech Clinical Research Infrastructure Network (CZECRIN; Brno, Czech Republic), the managers of all inpatient healthcare facilities within the network of the Central Adverse Events Reporting System of the Institute of Health Information and Statistics of the Czech Republic (IHIS-CR; Prague, Czech Republic), and all registered dentists through the Czech Dental Chamber (ČSK; Prague, Czech Republic) to contribute to this study by accessing the uniform resource locator (URL) of the digital questionnaire [22]. The awareness of the study was also raised by promotion on the websites and social media profiles of CZECRIN and the Faculty of Medicine [23]. The collected data are controlled by Masaryk University, and data acquisition and processing are in compliance with the General Data Protection Regulation (GDPR) [24]. 


\subsection{Participants}

Inclusion criteria for this study were Czech healthcare workers who were vaccinated with the Pfizer-BioNTech COVID-19 vaccine during the early vaccination phase of the governmental strategy (Phase 1A) [25]. The eligible participants should have received the latest dose of the vaccine, either the first or the second dose, no more than thirty days before filling in the questionnaire. Non-healthcare workers who were vaccinated during Phase 1A and the healthcare workers who were vaccinated in February 2021 by Moderna COVID-19 vaccine and Oxford/AstraZeneca COVID-19 vaccine were excluded from this report. Participation in this study was not compensated financially or by any other incentives.

\subsection{Instrument}

The self-administered questionnaire of this study was composed of twenty mandatory multiple-choice items and eight conditional multiple-choice items, and it was adapted from previous studies on the oral side effects of various vaccines by the authors [9,26]. A panel of four experts in oral medicine, maxillofacial surgery, and infectious diseases were formed to review the questionnaire draft and to assess its content validity. We used an iterative discussion to finalize the questionnaire. Later, the reliability of the questionnaire was evaluated by a group of eighteen recently vaccinated healthcare workers, who filled in the questionnaire twice with a minimum interval of two weeks. The result of the test re-test of the provisional instrument yielded substantial reliability, with a mean Cohen's kappa coefficient of $0.89 \pm 0.13(0.54-1)$ (Table 1$)$.

Table 1. The results of test re-test reliability of the instrument of the "Oral Side Effects of COVID-19 Vaccine" study (OSECV) ${ }^{1}$.

\begin{tabular}{cccc}
\hline Participant & $\kappa$ Coefficient & Participant & $\kappa$ Coefficient \\
\hline No. 1 & 0.821 & No. 10 & 0.540 \\
No. 2 & 0.842 & No. 11 & 1.000 \\
No. 3 & 0.777 & No. 12 & 1.000 \\
No. 4 & 0.940 & No. 13 & 1.000 \\
No. 5 & 1.000 & No. 14 & 1.000 \\
No. 6 & 1.000 & No. 15 & 0.937 \\
No. 7 & 0.934 & No. 16 & 0.872 \\
No. 8 & 0.758 & No. 17 & 0.868 \\
No. 9 & 1.000 & No. 18 & 0.762 \\
\hline
\end{tabular}

${ }^{1}$ Cohen's Kappa statistic ( $\left.\kappa\right)$ : $0.01-0.20$ as none to slight; $0.21-0.40$ as fair; $0.41-0.60$ as moderate; $0.61-0.80$ as substantial; and $0.81-1.00$ as perfect agreement [27].

The questionnaire was divided into four main categories: (i) demographic data including gender, age, region, profession, and length of work experience; (ii) medical anamnesis including medical comorbidities and medications; (iii) COVID-19 related anamnesis including vaccination date and the number of doses, previous infection, and exposure to infected cases; and (iv) vaccine side effects including general side effects, oral side effects, and skin-related side effects (Supplementary Materials Table S1).

\subsection{Ethical Considerations}

The study was reviewed and approved by the Ethics Committee of the Faculty of Medicine at Masaryk University on 20 January 2021 (Ref. 2/2021). Digital informed consent had been obtained from each participant prior to participation. The participants were allowed to withdraw from the study at any moment without justifying, and no data were saved before the participant submitted their answers completely.

\subsection{Statistical Analysis}

All statistical tests were executed using the Statistical Package for the Social Sciences (SPSS) version 27.0 (SPSS Inc. Chicago, IL, USA, 2020). Primarily, descriptive statistics 
were carried out for the demographic variables (gender, age, profession, length of work experience, and region), and medical anamnesis (non-communicable diseases, and medical treatments), COVID-19-related anamnesis (number of doses, interval between doses, previous infection, patency period, and previous exposure to COVID-19 cases), and vaccine side effects (general side effects, oral side effects, and skin-related side effects) were represented by frequencies, percentages, means and standard deviations. Consequently, inferential statistics were performed to assess the association between side effects and medical anamnesis, and the association of various side effects and each other using the chi-squared test $\left(\chi^{2}\right)$, Student's $t$-test, one-way analysis of variance (ANOVA), and Pearson's correlation test $(r)$, with a confidence level of $95 \%$ and significance value $p \leq 0.05$. Strengths of correlation are verbally described by the value of $(r)$ 0.00-0.19 "very weak"; 0.20-0.39 "weak"; 0.40-0.59 "moderate"; 0.60-0.79 "strong"; 0.80-1.0 "very strong".

\section{Results}

\subsection{Demographic Characteristics}

A total of 922 participants filled in the questionnaire properly by 27 February 2021. Nineteen participants were administrative staff at healthcare facilities; therefore, they were vaccinated, but they did not meet the study's inclusion criteria. Similarly, twentyeight participants received either the Moderna COVID-19 vaccine or Oxford/AstraZeneca COVID-19 vaccine; therefore, they were excluded from this report. Three participants did not submit their age properly; therefore, they were omitted from the inferential statistics based on age groups.

A total of 877 participants were included in the final analyses; $776(88.5 \%)$ were females, $100(11.4 \%)$ were males, and 1 (0.1\%) preferred not to state their gender. Their mean age was $42.56 \pm 10.5$ years old, and it ranged between 19 and 78 years old with a median of 43 years old. Given the fact that the median age of this study's participants corresponds with the mean age of healthcare workers in the Czech Republic, which is between 40 and 45 years old, the sample's median age (43 years old) had been used as a cut-off to present the anamnestic characteristics and the COVID-19 vaccine side effects of the participants $[28,29]$ (Table 2).

On comparing the number of participants to the total number of healthcare workers per region, reported by IHIS-CR, the mean density was $2.95 \pm 2.22$ responses per 1000 healthcare workers [30]. The highest density was in the South-Moravian region with 9.86 response per 1000 healthcare workers; the lowest was in the South Bohemian region with 1.51 response per 1000 healthcare workers (Figure 1).

\subsection{Medical Anamneses}

A total of 271 (31\%) participants reported having at least one non-communicable disease (NCD) with a statistically significant difference between the $\leq 43$-year-old group and the >43-year-old group: $105(23.9 \%)$ vs. $166(38.2 \%)$, respectively. Out of all the chronically ill participants, $100(36.9 \%)$ reported chronic hypertension, $69(25.6 \%)$ thyroid disease, 59 (21.8\%) asthma, 23 (8.5\%) diabetes mellitus type-2, 16 (5.9\%) cardiac disease, 16 (5.9\%) allergy, 13 (4.8\%) rheumatoid arthritis, 12 (4.4\%) bowel disease, 11 (4.1\%) blood disease, $11(4.1 \%)$ neurologic disease, $8(3 \%)$ psychological distress, $6(2.2 \%)$ renal disease, $5(1.8 \%)$ chronic obstructive pulmonary disease (COPD), 4 (1.5\%) cancer, $3(1.1 \%)$ diabetes mellitus type-1, 2 (0.7\%) hepatologic disease, and 1 (0.4\%) ophthalmologic disease. Across the age groups, the total number of NCDs was significantly higher in the $>43$-year-old group $(1.39 \pm 0.66)$ than the $\leq 43$-year-old group $(1.22 \pm 0.46)$ with a significance value of 0.020 (Table 3).

The chi-squared test revealed a statistically significant difference in the distribution of some NCDs between both age groups, e.g., chronic hypertension, psychological distress, blood disease, and diabetes mellitus type-2 with significance values less than $0.0001,0.004$, 0.018 , and 0.028 , respectively. 
Table 2. Demographic characteristics of the Czech healthcare workers who received the PfizerBioNTech COVID-19 vaccine, January-February 2021.

\begin{tabular}{|c|c|c|c|}
\hline Variable & Outcome & Frequency & Percentage \\
\hline \multirow[t]{3}{*}{ Gender } & Female & 776 & $88.5 \%$ \\
\hline & Male & 100 & $11.4 \%$ \\
\hline & Prefer not to say & 1 & $0.1 \%$ \\
\hline \multirow[t]{2}{*}{ Age } & $\leq 43$ years old & 439 & $50.2 \%$ \\
\hline & $>43$ years old & 435 & $49.8 \%$ \\
\hline \multirow[t]{13}{*}{ Profession } & Registered Nurse & 540 & $61.6 \%$ \\
\hline & Physician & 77 & $8.8 \%$ \\
\hline & Practice Nurse & 75 & $8.6 \%$ \\
\hline & Lab Worker & 46 & $5.2 \%$ \\
\hline & Paramedic & 26 & $3.0 \%$ \\
\hline & Dentist & 24 & $2.7 \%$ \\
\hline & Midwife & 23 & $2.6 \%$ \\
\hline & Pharmacist & 21 & $2.4 \%$ \\
\hline & Physiotherapist & 19 & $2.2 \%$ \\
\hline & Radiological Assistant & 12 & $1.4 \%$ \\
\hline & Psychologist & 8 & $0.9 \%$ \\
\hline & Dietitian & 5 & $0.6 \%$ \\
\hline & Dental Hygienist & 1 & $0.1 \%$ \\
\hline \multirow{4}{*}{ Length of Work Experience } & $1-5$ years & 134 & $15.3 \%$ \\
\hline & $6-10$ years & 88 & $10.0 \%$ \\
\hline & $11-20$ years & 188 & $21.4 \%$ \\
\hline & $>20$ years & 467 & $53.2 \%$ \\
\hline \multirow[t]{14}{*}{ Region } & South-Moravian & 301 & $34.3 \%$ \\
\hline & Prague & 105 & $12.0 \%$ \\
\hline & Moravian-Silesian & 92 & $10.5 \%$ \\
\hline & Hradec Kralove & 78 & $8.9 \%$ \\
\hline & Central Bohemian & 70 & $8.0 \%$ \\
\hline & Olomouc & 51 & $5.8 \%$ \\
\hline & Plzen & 29 & $3.3 \%$ \\
\hline & Usti nad Labem & 29 & $3.3 \%$ \\
\hline & Zlin & 25 & $2.9 \%$ \\
\hline & Vysočina & 23 & $2.6 \%$ \\
\hline & South Bohemian & 22 & $2.5 \%$ \\
\hline & Pardubice & 21 & $2.4 \%$ \\
\hline & Karlovy Vary & 17 & $1.9 \%$ \\
\hline & Liberec & 14 & $1.6 \%$ \\
\hline
\end{tabular}

A total of 384 (44\%) participants reported receiving at least one medical treatment at the time of filling in the questionnaire, with a statistically significant difference between the $\leq 43$-year-old group and the >43-year-old group: 144 (32.8\%) vs. 240 (55.2\%), respectively. Out of all the regularly taken drugs, antihypertensive drugs were taken by $98(25.5 \%)$, followed by thyroid hormones replacement by $90(23.4 \%)$, antihistamine by $75(19.6 \%)$, antidepressant by $45(11.7 \%)$, contraceptives by $21(5.5 \%)$, common analgesics $19(4.9 \%)$, nonsteroidal anti-inflammatory (NSAID) by $15(3.9 \%)$, antidiabetics by $14(3.6 \%)$, antireflux by $13(3.4 \%)$, cholesterol-lowering by $12(3.1 \%)$, immunosuppressive by $8(2.1 \%)$, anti-asthma by $7(1.8 \%)$, venous insufficiency by $6(1.6 \%)$, anticoagulants by $6(1.6 \%)$, antiepileptics by $6(1.6 \%)$, corticosteroids by $6(1.6 \%)$, opioid analgesics by $3(0.8 \%)$, antibiotics by $2(0.5 \%)$, and other drugs by $18(4.7 \%)$, including bronchodilators, antifungals, antidiuretic, estrogen hormone, chemotherapy, vitamin $\mathrm{D}$, and interferon. Across the age groups, the total number of taken drugs was insignificantly lower in the $>43$-year-old group (1.20 \pm 0.51$)$ than the $\leq 43$-year-old group $(1.24 \pm 0.55)$ (Table 4$)$. 


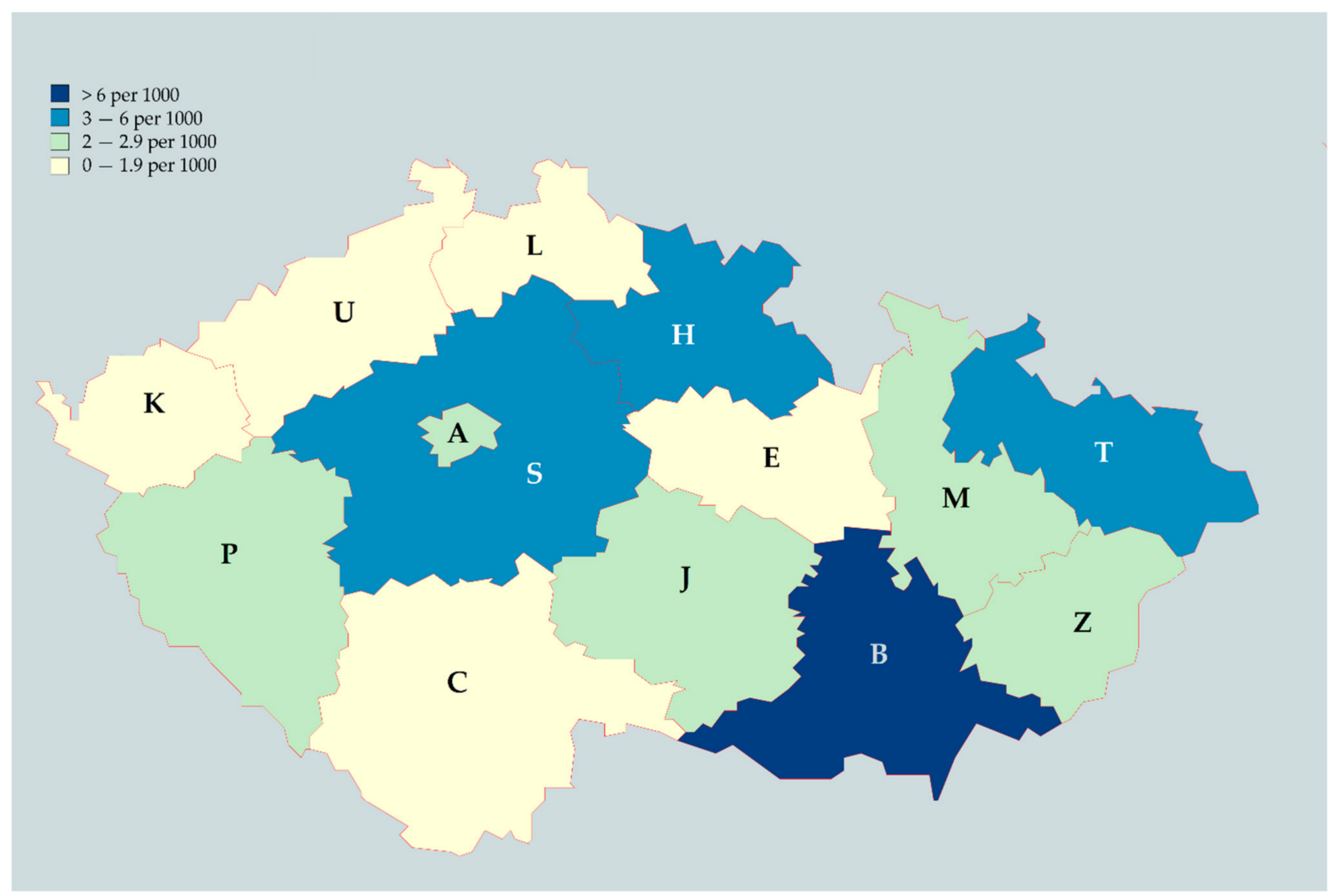

Figure 1. Regional density of the participating Czech healthcare workers; (A) Prague; (S) Central Bohemian; (C) South Bohemian; (J) Vysočina; (P) Plzen; (K) Karlovy Vary; (U) Usti nad Labem; (L) Liberec; (H) Hradec Kralove; (E) Pardubice; (M) Olomouc; (T) Moravian-Silesian; (B) South-Moravian; (Z) Zlin; January-February 2021.

Table 3. Non-communicable diseases of vaccinated healthcare workers in the Czech Republic, January-February 2021.

\begin{tabular}{|c|c|c|c|c|}
\hline Disease & $\leq 43$ Years Old & $>43$ Years Old & Total & Significance $^{1}$ \\
\hline Allergy & $9(8.6 \%)$ & $7(4.2 \%)$ & $16(5.9 \%)$ & 0.138 \\
\hline Asthma & $26(24.8 \%)$ & $33(19.9 \%)$ & $59(21.8 \%)$ & 0.343 \\
\hline Blood Disease & $8(7.6 \%)$ & $3(1.8 \%)$ & $11(4.1 \%)$ & 0.018 \\
\hline Bowel Disease & $7(6.7 \%)$ & $5(3.0 \%)$ & $12(4.4 \%)$ & 0.154 \\
\hline Cancer & $0(0.0 \%)$ & $4(2.4 \%)$ & $4(1.5 \%)$ & 0.109 \\
\hline Cardiac Disease & $4(3.8 \%)$ & $12(7.2 \%)$ & $16(5.9 \%)$ & 0.245 \\
\hline Chronic Hypertension & $21(20.0 \%)$ & $79(47.6 \%)$ & $100(36.9 \%)$ & $<0.0001$ \\
\hline COPD & $0(0.0 \%)$ & $5(3.0 \%)$ & $5(1.8 \%)$ & 0.073 \\
\hline Diabetes Mellitus-I & $2(1.9 \%)$ & $1(0.6 \%)$ & $3(1.1 \%)$ & 0.318 \\
\hline Diabetes Mellitus-II & $4(3.8 \%)$ & $19(11.4 \%)$ & $23(8.5 \%)$ & 0.028 \\
\hline Hepatologic Disease & $2(1.9 \%)$ & $0(0.0 \%)$ & $2(0.7 \%)$ & 0.074 \\
\hline Psychological Distress & $7(6.7 \%)$ & $1(0.6 \%)$ & $8(3.0 \%)$ & 0.004 \\
\hline Neurologic Disease & $2(1.9 \%)$ & $9(5.4 \%)$ & $11(4.1 \%)$ & 0.153 \\
\hline $\begin{array}{l}\text { Ophthalmologic } \\
\text { Disease }\end{array}$ & $0(0.0 \%)$ & $1(0.6 \%)$ & $1(0.4 \%)$ & 0.426 \\
\hline Renal Disease & $2(1.9 \%)$ & $4(1.8 \%)$ & $6(2.2 \%)$ & 0.783 \\
\hline Rheumatoid Arthritis & $3(2.9 \%)$ & $10(6 \%)$ & $13(4.8 \%)$ & 0.235 \\
\hline Thyroid Disease & $31(29.5 \%)$ & $38(22.9 \%)$ & $69(25.5 \%)$ & 0.222 \\
\hline $\begin{array}{c}\text { Number of NCDs } \\
(1-17)\end{array}$ & $1.22 \pm 0.46$ & $1.39 \pm 0.66$ & $1.32 \pm 0.59$ & 0.026 \\
\hline Total & $105(23.9 \%)$ & $166(38.2 \%)$ & $271(31 \%)$ & 0.020 \\
\hline
\end{tabular}

${ }^{1}$ Chi-square test and Student's $t$-test were used with a significance level of $<0.05$. Bold format highlight the significantly different diseases across age groups. 
Table 4. Regularly taken drugs by the vaccinated healthcare workers in the Czech Republic, January-February 2021.

\begin{tabular}{|c|c|c|c|c|}
\hline Drug & $\leq 43$ Years Old & $>43$ Years Old & Total & Significance $^{1}$ \\
\hline Anti-asthma & $4(2.8 \%)$ & $3(1.3 \%)$ & $7(1.8 \%)$ & 0.279 \\
\hline Antibiotics & $1(0.7 \%)$ & $1(0.4 \%)$ & $2(0.5 \%)$ & 0.714 \\
\hline Anticoagulant & $1(0.7 \%)$ & $5(2.1 \%)$ & $6(1.6 \%)$ & 0.288 \\
\hline Antidepressant & $19(13.2 \%)$ & $26(10.8 \%)$ & $45(11.7 \%)$ & 0.486 \\
\hline Antidiabetic & $3(2.1 \%)$ & $11(4.6 \%)$ & $14(3.6 \%)$ & 0.206 \\
\hline Antiepileptic & $4(2.8 \%)$ & $2(0.8 \%)$ & $6(1.6 \%)$ & 0.138 \\
\hline Antihistamine & $37(25.7 \%)$ & $38(15.8 \%)$ & $75(19.5 \%)$ & 0.018 \\
\hline Antihypertensive & $23(16.0 \%)$ & $75(31.3 \%)$ & $98(25.5 \%)$ & 0.001 \\
\hline Anti-Reflux & $6(4.2 \%)$ & $7(2.9 \%)$ & $13(3.4 \%)$ & 0.512 \\
\hline Immunosuppressive & $2(1.4 \%)$ & $6(2.5 \%)$ & $8(2.1 \%)$ & 0.460 \\
\hline Cholesterol-lowering & $3(2.1 \%)$ & $9(3.8 \%)$ & $12(3.1 \%)$ & 0.363 \\
\hline Common Analgesic & $7(4.9 \%)$ & $12(5.0 \%)$ & $19(4.9 \%)$ & 0.952 \\
\hline Contraceptive & $15(10.4 \%)$ & $6(2.5 \%)$ & $21(5.5 \%)$ & 0.001 \\
\hline Corticosteroid & $2(1.4 \%)$ & $4(1.7 \%)$ & $6(1.6 \%)$ & 0.832 \\
\hline Nonsteroidal anti-inflammatory (NSAID) & $6(4.2 \%)$ & $9(3.8 \%)$ & $15(3.9 \%)$ & 0.838 \\
\hline Opioid Analgesic & $2(1.4 \%)$ & $1(0.4 \%)$ & $3(0.8 \%)$ & 0.295 \\
\hline Thyroid Hormones & $35(24.3 \%)$ & $55(22.9 \%)$ & $90(23.4 \%)$ & 0.756 \\
\hline Venous Insufficiency & $4(2.8 \%)$ & $2(0.8 \%)$ & $6(1.6 \%)$ & 0.137 \\
\hline Other & $5(3.5 \%)$ & $13(5.4 \%)$ & $18(4.7 \%)$ & 0.383 \\
\hline Number of Drugs (1-19) & $1.24 \pm 0.55$ & $1.20 \pm 0.51$ & $1.21 \pm 0.52$ & 0.392 \\
\hline Total & $144(32.8 \%)$ & $240(55.2 \%)$ & $384(43.9 \%)$ & $<0.0001$ \\
\hline
\end{tabular}

${ }^{1}$ Chi-squared test and ANOVA were used with a significance level of $<0.05$.

The chi-squared test revealed a statistically significant difference in the distribution of some taken drugs between both age groups, e.g., antihypertensive drugs, contraceptives, and antihistamine drugs, with significance values of $0.001,0.001$, and 0.018 , respectively.

\subsection{COVID-19-Related Anamnesis}

By the time of filling in the questionnaire, the vast majority of the participants had received both doses of the Pfizer-BioNTech COVID-19 vaccine (93.6\%), while 56 (6.4\%) had received the first dose only. The interval between the first dose and the second dose ranged between 7 and 55 days, with a median of 21 days. The difference was statistically insignificant across the age groups, with a slight longer interval among the $\leq 43$-year-old group ( $22.69 \pm 5.14$ days) compared to the $>43$-year-old group ( $22.48 \pm 4.7$ days).

Although 169 (19.3\%) participants had been previously infected by COVID-19, the patency period between the recovery date and the first vaccine dose ranged between 7 and 270 days with a median of 65 days. Regarding the exposure to COVID-19 cases, a total of $617(70.6 \%)$ participants reported that they had been in contact with COVID-19 cases previously: $317(72.2 \%)$ of the $\leq 43$-year-old group and $300(69 \%)$ of the $>43$-year-old group, without statistical significance $(p=0.293)$ (Table 5).

Table 5. COVID-19-related anamnesis of vaccinated healthcare workers in the Czech Republic, January-February 2021.

\begin{tabular}{|c|c|c|c|c|c|}
\hline Variable & Outcome & $\leq 43$ Years Old & $>43$ Years Old & Total & Significance $^{1}$ \\
\hline \multirow[t]{2}{*}{ Number of doses } & One dose & $26(5.9 \%)$ & $30(6.9 \%)$ & $56(6.4 \%)$ & \multirow[t]{2}{*}{0.557} \\
\hline & Two doses & $413(94.1 \%)$ & $404(93.1 \%)$ & $818(93.6 \%)$ & \\
\hline Interval & (days) & $22.69 \pm 5.14$ & $22.48 \pm 4.7$ & $22.58 \pm 4.92$ & 0.551 \\
\hline COVID-19 infection & Yes & $90(20.5 \%)$ & $79(18.2 \%)$ & $169(19.3 \%)$ & 0.381 \\
\hline Patency period & (days) & $77.78 \pm 54.69$ & $72.44 \pm 45.16$ & $75.42 \pm 50.58$ & 0.534 \\
\hline Previous COVID-19 exposure & Yes & $317(72.2 \%)$ & $300(69 \%)$ & $617(70.6 \%)$ & 0.293 \\
\hline
\end{tabular}

\footnotetext{
${ }^{1}$ Chi-squared test and Student's $t$-test were used with a significance level of $<0.05$.
} 


\subsection{COVID-19 Vaccine Reported Side Effects}

\subsubsection{Prevalence of General Side Effects}

A total of 814 (93.1\%) participants reported having at least one side effect following the COVID-19 vaccine. The prevalence of side effects was slightly higher in the $\leq 43$-year-old group $(94.8 \%)$ than the $>43$-year-old group $(91.5 \%)$. The most common side effect was injection site pain $(89.8 \%)$, followed by fatigue $(62.2 \%)$, headache $(45.6 \%)$, muscle pain $(37.1 \%)$, and chills $(33.9 \%)$. All the reported side effects were more prevalent in the $\leq 43-$ year-old group than the $>43$-year-old group, with a statistically significant difference in the case of injection site pain ( $93.3 \%$ vs. $86.2 \%$ ), headache ( $50.7 \%$ vs. $40.2 \%)$, fatigue $(65.9 \%$ vs. $58.3 \%$ ), muscle pain ( $40.9 \%$ vs. $33.2 \%$ ), and feeling unwell ( $26 \%$ vs. $19.8 \%$ ).

Regarding the general side effects' duration, $45.1 \%$ of them lasted for 1 day, while $35.8 \%$ lasted for 3 days, $9.4 \%$ lasted for 5 days, 5.3\% lasted for one week, 3\% lasted for over a week, and $1.4 \%$ for over a month. The severe side effects that required medical intervention was reported by only $1.3 \%$ of the whole study group (Table 6 ).

Table 6. Prevalence of the general side effects of Pfizer-BioNTech COVID-19 vaccine among healthcare workers in the Czech Republic, January-February 2021.

\begin{tabular}{|c|c|c|c|c|c|}
\hline Variable & Outcome & $\leq 43$ Years Old & $>43$ Years Old & Total & Significance $^{1}$ \\
\hline \multirow[t]{12}{*}{ Side Effect } & Injection site pain & $388(93.3 \%)$ & $343(86.2 \%)$ & $731(89.8 \%)$ & 0.001 \\
\hline & Fatigue & $274(65.9 \%)$ & $232(58.3 \%)$ & $506(62.2 \%)$ & 0.026 \\
\hline & Headache & $211(50.7 \%)$ & $160(40.2 \%)$ & $371(45.6 \%)$ & 0.003 \\
\hline & Muscle pain & $170(40.9 \%)$ & $132(33.2 \%)$ & $302(37.1 \%)$ & 0.023 \\
\hline & Chills & $153(36.8 \%)$ & $123(30.9 \%)$ & $276(33.9 \%)$ & 0.077 \\
\hline & Joint pain & $119(28.6 \%)$ & 107 (26.9\%) & $226(27.8 \%)$ & 0.584 \\
\hline & Injection site swelling & $108(26.0 \%)$ & $100(25.1 \%)$ & $208(25.6 \%)$ & 0.785 \\
\hline & Injection site redness & $106(25.5 \%)$ & $81(20.4 \%)$ & $187(23.0 \%)$ & 0.082 \\
\hline & Feeling unwell & $108(26.0 \%)$ & $79(19.8 \%)$ & $187(23 \%)$ & 0.038 \\
\hline & Fever & $101(24.3 \%)$ & $76(19.1 \%)$ & $177(21.7 \%)$ & 0.073 \\
\hline & Lymphadenopathy & $72(17.3 \%)$ & $60(15.1 \%)$ & $132(16.2 \%)$ & 0.388 \\
\hline & Nausea & $61(14.7 \%)$ & $45(11.3 \%)$ & $106(13.0 \%)$ & 0.155 \\
\hline Number of Side Effects & $(1-12)$ & $4.50 \pm 2.596$ & $3.87 \pm 2.599$ & $4.19 \pm 2.615$ & 0.001 \\
\hline Total & & $416(94.8 \%)$ & $398(91.5 \%)$ & $814(93.1 \%)$ & 0.056 \\
\hline \multirow[t]{6}{*}{ Duration } & 1 day & $196(47.2 \%)$ & $168(42.7 \%)$ & $364(45.1 \%)$ & \\
\hline & 3 days & $159(38.3 \%)$ & $130(33.2 \%)$ & $289(35.8 \%)$ & \\
\hline & 5 days & $31(7.5 \%)$ & $45(11.5 \%)$ & $76(9.4 \%)$ & \\
\hline & 1 week & $17(4.1 \%)$ & $26(6.6 \%)$ & $43(5.3 \%)$ & \\
\hline & >1 week & $8(1.9 \%)$ & $16(4.1 \%)$ & $24(3.0 \%)$ & \\
\hline & $>1$ month & $4(1.0 \%)$ & $7(1.8 \%)$ & $11(1.4 \%)$ & \\
\hline Severe Side Effects & & $5(1.1 \%)$ & $6(1.4 \%)$ & $11(1.3 \%)$ & 0.747 \\
\hline
\end{tabular}

\subsubsection{Prevalence of Reported Oral Side Effects}

A total of 114 (13\%) participants reported to have at least one oral side effect following the Pfizer-BioNTech COVID-19 vaccine. The prevalence of oral side effects was insignificantly higher in the $\leq 43$-year-old group $(13.4 \%)$ than the $>43$-year-old group $(12.6 \%)$. The most common oral side effect was blisters (36\%), followed by halitosis $(25.4 \%)$, ulcers $(14 \%)$, bleeding gingiva (11.4\%), and white/red plaque (10.5\%).

However, there were no statistically significant differences between the age groups: white/red plaque ( $10.9 \%$ vs. $10.2 \%)$, burning gingiva (9.1\% vs. $8.5 \%)$, angular cheilitis ( $5.5 \%$ vs. $3.4 \%)$, tongue tingling ( $5.5 \%$ vs. $3.4 \%)$, taste disturbance $(5.5 \%$ vs. $1.7 \%)$, vesicles $(3.6 \%$ vs. $3.4 \%)$, and xerostomia (3.6\% vs. $1.7 \%$ ) were more prevalent in the $>43$-year-old group than the $\leq 43$-year-old group. On the other hand, blisters ( $37.3 \%$ vs. $34.5 \%)$, halitosis ( $28.8 \%$ vs. $21.8 \%$ ), ulcers ( $16.9 \%$ vs. $10.9 \%)$, bleeding gingiva (13.6\% vs. $9.1 \%)$, and swollen 
lips (5.1\% vs. $1.8 \%)$ were more prevalent in the $\leq 43$-year-old group compared to the $>43$-year-old group.

Regarding oral side effects' onset, $28.6 \%$ of them emerged within the first week postvaccination, while $26.8 \%$ emerged within $1-3$ days post-vaccination, $18.8 \%$ within the third week post-vaccination, $16.1 \%$ within the second week post-vaccination, and $9.8 \%$ within the fourth week post-vaccination.

The most common location of ulcers, blisters, and vesicles was the lips (74.1\%), followed by labial and buccal mucosa $(14.8 \%)$, tongue (13\%), palate $(9.3 \%)$, and gingiva (9.3\%). The difference between the age groups was statistically insignificant; however, lips were affected in $80 \%$ of the $>43$-year-old group versus $69 \%$ of the $\leq 43$-year-old group. All (100\%) of the $>43$-year-old group participants had one affected location, whereas $72.4 \%$ of the $\leq 43$-year-old group participants had one affected location, $20.7 \%$ had two affected locations, $3.4 \%$ had three affected locations, and $3.4 \%$ had four affected locations. In the case of white/red plaque, the most common location was the tongue dorsum (75\%), followed by soft palate (16.7\%) and labial and buccal mucosa (8.3\%) (Table 7).

Table 7. Prevalence of oral side effects of Pfizer-BioNTech COVID-19 vaccine among healthcare workers in the Czech Republic, January-February 2021.

\begin{tabular}{|c|c|c|c|c|c|}
\hline Variable & Outcome & $\leq 43$ Years Old & $>43$ Years Old & Total & Significance $^{1}$ \\
\hline \multirow[t]{12}{*}{ Side Effect } & Blisters & $22(37.3 \%)$ & $19(34.5 \%)$ & $41(36 \%)$ & 0.760 \\
\hline & Halitosis & $17(28.8 \%)$ & $12(21.8 \%)$ & $29(25.4 \%)$ & 0.391 \\
\hline & Ulcers & $10(16.9 \%)$ & $6(10.9 \%)$ & $16(14.0 \%)$ & 0.354 \\
\hline & Bleeding gingiva & $8(13.6 \%)$ & $5(9.1 \%)$ & $13(11.4 \%)$ & 0.453 \\
\hline & White/red plaque & $6(10.2 \%)$ & $6(10.9 \%)$ & $12(10.5 \%)$ & 0.898 \\
\hline & Burning gingiva & $5(8.5 \%)$ & $5(9.1 \%)$ & $10(8.8 \%)$ & 0.907 \\
\hline & Angular cheilitis & $2(3.4 \%)$ & $3(5.5 \%)$ & $5(4.4 \%)$ & 0.591 \\
\hline & Tongue tingling & $2(3.4 \%)$ & $3(5.5 \%)$ & $5(4.4 \%)$ & 0.591 \\
\hline & Taste disturbance & $1(1.7 \%)$ & $3(5.5 \%)$ & $4(3.5 \%)$ & 0.276 \\
\hline & Vesicles & $2(3.4 \%)$ & $2(3.6 \%)$ & $4(3.5 \%)$ & 0.943 \\
\hline & Swollen lips & $3(5.1 \%)$ & $1(1.8 \%)$ & $4(3.5 \%)$ & 0.344 \\
\hline & Xerostomia & $1(1.7 \%)$ & $2(3.6 \%)$ & $3(2.6 \%)$ & 0.518 \\
\hline Number of Side Effects & $(1-12)$ & $1.41 \pm 0.098$ & $1.22 \pm 0.056$ & $1.32 \pm 0.603$ & 0.093 \\
\hline Total & & $59(13.4 \%)$ & $55(12.6 \%)$ & $114(13 \%)$ & 0.727 \\
\hline \multirow[t]{5}{*}{ Onset } & 1-3 days post-vaccination & $10(17.2 \%)$ & $20(37 \%)$ & $30(26.8 \%)$ & \\
\hline & 1st week post-vaccination & $19(32.8 \%)$ & $13(24.1 \%)$ & $32(28.6 \%)$ & \\
\hline & 2nd week post-vaccination & $11(19 \%)$ & $7(13.0 \%)$ & $18(16.1 \%)$ & \\
\hline & 3rd week post-vaccination & $11(19 \%)$ & $10(18.5 \%)$ & $21(18.8 \%)$ & \\
\hline & 4th week post-vaccination & $7(12.1 \%)$ & $4(7.4 \%)$ & $11(9.8 \%)$ & \\
\hline \multirow{5}{*}{$\begin{array}{l}\text { Location of ulcers, vesicles, } \\
\text { and blisters }\end{array}$} & Lips & $20(69.0 \%)$ & $20(80.0 \%)$ & $40(74.1 \%)$ & 0.356 \\
\hline & Labial/buccal mucosa & $6(20.7 \%)$ & $2(8.0 \%)$ & $8(14.8 \%)$ & 0.191 \\
\hline & Tongue & $6(20.7 \%)$ & $1(4.0 \%)$ & $7(13 \%)$ & 0.069 \\
\hline & Palate & $4(13.8 \%)$ & $1(4.0 \%)$ & $5(9.3 \%)$ & 0.216 \\
\hline & Gingiva & $4(13.8 \%)$ & $1(4.0 \%)$ & $5(9.3 \%)$ & 0.216 \\
\hline \multirow{5}{*}{$\begin{array}{l}\text { Number of ulcers, vesicles, } \\
\text { and blisters' locations }\end{array}$} & $(1-5)$ & $1.38 \pm 0.728$ & $1.00 \pm 0.00$ & $1.20 \pm 0.562$ & 0.012 \\
\hline & One location affected & $21(72.4 \%)$ & $25(100.0 \%)$ & $46(85.2 \%)$ & \\
\hline & Two locations affected & $6(20.7 \%)$ & $0(0.0 \%)$ & $6(11.1 \%)$ & \\
\hline & Three locations affected & $1(3.4 \%)$ & $0(0.0 \%)$ & $1(1.9 \%)$ & \\
\hline & Four locations affected & $1(3.4 \%)$ & $0(0.0 \%)$ & $1(1.9 \%)$ & \\
\hline \multirow{3}{*}{ Location of white/red plaque } & Tongue dorsum & $5(83.3 \%)$ & $4(66.7 \%)$ & $9(75.0 \%)$ & 0.505 \\
\hline & Soft palate & $1(16.7 \%)$ & $1(16.7 \%)$ & $2(16.7 \%)$ & 1.000 \\
\hline & Labial/buccal mucosa & $0(0.0 \%)$ & $1(16.7 \%)$ & $1(8.3 \%)$ & 0.296 \\
\hline
\end{tabular}

${ }^{1}$ Chi-squared test and ANOVA were used with a significance level of $<0.05$. 


\subsubsection{Prevalence of Skin-Related Side Effects}

A total of $45(5.2 \%)$ participants reported having at least one skin-related side effect following the COVID-19 vaccine. The prevalence of skin-related side effects was insignificantly higher in the $\leq 43$-year-old group $(6.2 \%)$ than the $>43$-year-old group $(4.1 \%)$. The most common skin-related side effect was rash $(62.2 \%)$, followed by urticaria $(22.2 \%)$, and other non-specific conditions (20\%). Upper limb was the most common location (60\%); chest and trunk were the second most common (33.3\%), and it was more common among the older age group than the younger age group (Table 8 ).

Table 8. Prevalence of skin-related side effects of the Pfizer-BioNTech COVID-19 vaccine among healthcare workers in the Czech Republic, January-February 2021.

\begin{tabular}{|c|c|c|c|c|c|}
\hline Variable & Outcome & $\leq 43$ Years Old & $>43$ Years Old & Total & Significance $^{1}$ \\
\hline \multirow[t]{3}{*}{ Side Effect } & Rash & $17(63.0 \%)$ & $11(61.1 \%)$ & $28(62.2 \%)$ & 0.900 \\
\hline & Urticaria & $7(25.9 \%)$ & $3(16.7 \%)$ & $10(22.2 \%)$ & 0.464 \\
\hline & Other & $4(14.8 \%)$ & $5(27.8 \%)$ & $9(20.0 \%)$ & 0.287 \\
\hline Number of Side Effects & $(1-3)$ & $1.03 \pm 0.183$ & $1.05 \pm 0.224$ & $1.04 \pm 0.198$ & 0.774 \\
\hline \multirow[t]{2}{*}{ Total } & & $27(6.2 \%)$ & $18(4.1 \%)$ & $45(5.2 \%)$ & 0.181 \\
\hline & Upper limb & $18(66.7 \%)$ & $9(50.0 \%)$ & $27(60.0 \%)$ & 0.264 \\
\hline \multirow[t]{4}{*}{ Location of skin-related side effects } & Chest/trunk & $8(29.6 \%)$ & $7(38.9 \%)$ & $15(33.3 \%)$ & 0.519 \\
\hline & Lower limb & $7(25.9 \%)$ & $3(16.7 \%)$ & $10(22.2 \%)$ & 0.464 \\
\hline & Face & $5(18.5 \%)$ & $4(22.2 \%)$ & $9(20.0 \%)$ & 0.761 \\
\hline & Back & $5(18.5 \%)$ & $3(16.7 \%)$ & $8(17.8 \%)$ & 0.874 \\
\hline Number of locations & $(1-5)$ & $1.59 \pm 0.797$ & $1.44 \pm 0.856$ & $1.53 \pm 0.815$ & 0.556 \\
\hline
\end{tabular}

${ }^{1}$ Chi-squared test and ANOVA were used with a significance level of $<0.05$.

\subsubsection{COVID-19 Vaccine Side Effects and Medical Anamneses}

The correlation test between the composite variables of side effects and medical anamnesis revealed a significant direct association between the total number of general side effects and the total number of medical treatments $(r=0.108 ; p=0.041)$. Age was significantly inversely correlated with the total number of general side effects $(r=-0.180$; $p<0.001$ ).

The general side effects' duration was significantly and directly correlated with age $(r=0.097 ; p=0.006)$, the total number of medical treatments $(r=0.122 ; p=0.021)$, and the total number of general side effects $(r=0.256 ; p<0.001)$. The total number of NCDs was directly correlated with age $(r=0.182 ; p=0.003)$, the total number of medical treatments $(r=0.232 ; p<0.001)$, and the total number of general side effects $(r=0.072 ; p=0.258)$.

Similarly, the oral side effects were inversely, but not significantly, correlated with age $(r=-0.164 ; p=0.086)$. The total number of oral side effects was positively correlated with the total number of NCDs $(r=0.045 ; p=0.790)$, the total number of medical treatments $(r=0.175 ; p=0.188)$, the total number of general side effects $(r=0.202 ; p=0.038)$, and the general side effects' duration $(r=0.279 ; p=0.004)$.

The oral side effects' onset was inversely correlated with the $(r=-0.202 ; p=0.033)$, and directly correlated with the total number of NCDs $(r=0.018 ; p=0.914)$, the total number of medical treatments $(r=0.168 ; p=0.208)$, the general side effects' duration $(r=0.025 ; p=0.794)$, and the total number of oral side effects $(r=0.143 ; p=0.138)$ (Table 9). 
Table 9. Correlation between medical anamneses and side effects of Pfizer-BioNTech COVID-19 vaccine among healthcare workers in the Czech Republic, January-February 2021.

\begin{tabular}{|c|c|c|c|c|c|c|c|c|}
\hline & & Age & $\begin{array}{l}\text { Chronic } \\
\text { Illnesses } \\
\text { Number }\end{array}$ & $\begin{array}{c}\text { Medical } \\
\text { Treatments } \\
\text { Number }\end{array}$ & $\begin{array}{c}\text { General SE } \\
\text { Number }\end{array}$ & $\begin{array}{c}\text { General SE } \\
\text { Duration }\end{array}$ & $\begin{array}{l}\text { Oral SE } \\
\text { Number }\end{array}$ & $\begin{array}{c}\text { Oral SE } \\
\text { Onset }\end{array}$ \\
\hline \multirow[t]{3}{*}{ Age } & $r$ & 1 & $0.180^{* *}$ & 0.016 & $-0.180^{* *}$ & $0.097 * *$ & -0.164 & $-0.202 *$ \\
\hline & Sig. & & 0.003 & 0.756 & 0.000 & 0.005 & 0.086 & 0.033 \\
\hline & $n$ & 874 & 271 & 384 & 814 & 807 & 111 & 112 \\
\hline \multirow{3}{*}{$\begin{array}{l}\text { Chronic } \\
\text { Illnesses } \\
\text { Number }\end{array}$} & $r$ & $0.180 * *$ & 1 & $0.232 * *$ & 0.072 & 0.088 & 0.045 & 0.018 \\
\hline & Sig. & 0.003 & & 0.000 & 0.258 & 0.167 & 0.790 & 0.914 \\
\hline & $n$ & 271 & 272 & 249 & 249 & 246 & 38 & 37 \\
\hline \multirow{3}{*}{$\begin{array}{c}\text { Medical } \\
\text { Treatments } \\
\text { Number }\end{array}$} & $r$ & 0.016 & $0.232 * *$ & 1 & 0.108 * & 0.122 * & 0.175 & 0.168 \\
\hline & Sig. & 0.756 & 0.000 & & 0.041 & 0.021 & 0.188 & 0.208 \\
\hline & $n$ & 384 & 249 & 386 & 359 & 354 & 58 & 58 \\
\hline \multirow{3}{*}{$\begin{array}{c}\text { General SE } \\
\text { Number }\end{array}$} & $r$ & $-0.180^{* *}$ & 0.072 & 0.108 * & 1 & $0.256^{* *}$ & $0.202 *$ & -0.054 \\
\hline & Sig. & 0.000 & 0.258 & 0.041 & & 0.000 & 0.038 & 0.574 \\
\hline & $n$ & 814 & 249 & 359 & 817 & 809 & 106 & 109 \\
\hline \multirow{3}{*}{$\begin{array}{c}\text { General SE } \\
\text { Duration }\end{array}$} & $r$ & $0.097 * *$ & 0.088 & 0.122 * & $0.256^{* *}$ & 1 & 0.279 ** & 0.025 \\
\hline & Sig. & 0.005 & 0.167 & 0.021 & 0.000 & & 0.004 & 0.794 \\
\hline & $n$ & 807 & 246 & 354 & 809 & 809 & 106 & 107 \\
\hline \multirow{3}{*}{$\begin{array}{l}\text { Oral SE } \\
\text { Number }\end{array}$} & $r$ & -0.164 & 0.045 & 0.175 & $0.202 *$ & $0.279 * *$ & 1 & 0.143 \\
\hline & Sig. & 0.086 & 0.790 & 0.188 & 0.038 & 0.004 & & 0.138 \\
\hline & $n$ & 111 & 38 & 58 & 106 & 106 & 111 & 109 \\
\hline \multirow{3}{*}{$\begin{array}{l}\text { Oral SE } \\
\text { Onset }\end{array}$} & $r$ & $-0.202 *$ & 0.018 & 0.168 & -0.054 & 0.025 & 0.143 & 1 \\
\hline & Sig. & 0.033 & 0.914 & 0.208 & 0.574 & 0.794 & 0.138 & \\
\hline & $n$ & 112 & 37 & 58 & 109 & 107 & 109 & 113 \\
\hline
\end{tabular}

* Correlation is significant at the 0.05 level (2-tailed); ${ }^{* *}$ Correlation is significant at the 0.01 level (2-tailed); SE, side effects.

\subsubsection{Risk Factors of COVID-19 Vaccine Side Effects}

Injection site pain was significantly more prevalent among the younger age group $(p=0.001)$, the healthcare workers with shorter work experience $(p=0.009)$, the participants with diabetes mellitus type-2 $(p=0.019)$, and the participants receiving antidiabetic drugs $(p=0.038)$ and venous insufficiency drugs $(p=0.028)$.

Injection site swelling was significantly more prevalent among females $(p=0.021)$, the participants receiving corticosteroids $(p=0.028)$, and the previously infected participants $(p=0.030)$.

Injection site redness was significantly more prevalent among the participants with allergies $(p=0.018)$, and the participants receiving antihistamine drugs $(p=0.013)$, and corticosteroids $(p=0.001)$. It was also significantly associated with the total number of $\operatorname{NCDs}(p=0.010)$, and the total number of medical treatments $(p=0.031)$.

Fatigue was significantly more prevalent among the young age group $(p=0.024)$, the healthcare workers with shorter work experience $(p=0.026)$, and the participants not receiving cholesterol-lowering drugs $(p=0.010)$.

Headache was significantly more prevalent among females $(p=0.006)$, the young age group $(p=0.003)$, the healthcare workers with shorter work experience $(p=0.007)$, and the participants receiving antihistamine drugs $(p=0.007)$.

Nausea was significantly more prevalent among females $(p=0.015)$, the healthcare workers with shorter work experience $(p=0.029)$, and the participants receiving antihistamine drugs $(p=0.027)$, and antidepressants $(p=0.013)$.

Feeling unwell was significantly more prevalent among the younger age group $(p=0.032)$, the healthcare workers with shorter work experience $(p=0.003)$, and the participants with hepatologic disease $(p=0.006)$ and renal disease $(p=0.008)$.

Muscle pain was significantly more prevalent among the younger age group $(p=0.025)$, the participants receiving antidepressants $(p=0.053)$ and antiepileptics $(p=0.018)$, and the previously exposed participants to COVID-19 $(p=0.007)$. 
Joint pain was significantly more prevalent among the participants with NCDs $(p=0.041)$ and hepatologic disease $(p=0.041)$, the participants receiving antibiotics $(p=0.034)$ and antidepressants $(p=0.021)$, and the previously exposed participants $(p=0.027)$.

Fever was significantly more prevalent among the healthcare workers with shorter work experience $(p=0.014)$, the participants with NCDs $(p=0.033)$ and asthma $(p=0.008)$, the participants receiving antihistamine drugs $(p=0.011)$ and NSAIDs $(p=0.035)$, and the previously infected participants $(p=0.023)$.

Chills were significantly more prevalent among the healthcare workers with shorter work experience $(p=0.005)$, and the participants receiving antihistamine drugs $(p=0.014)$ and NSAIDs $(p=0.029)$.

Lymphadenopathy was significantly more prevalent among the participants receiving antihistamine drugs $(p=0.019)$.

\subsubsection{Number of Doses and Side Effects' Prevalence}

The prevalence of injection site pain, swelling, redness, fatigue, headache, nausea, muscle pain, lymphadenopathy was higher among the participants who received two doses compared to the participants with one dose. Injection site redness was the only general side effect that was significantly more prevalent in the two-doses group $(23.9 \%)$ than the one-dose group (8\%), with a $p$-value of 0.10 .

The oral side effects were insignificantly more prevalent in the one dose group, e.g., ulcers, white/red plaque, and bleeding gingiva. In contrast, vesicles, blisters, burning gingiva, swollen lips, angular cheilitis, xerostomia, taste disturbance, and tongue tingling were more common in the two-dose group. The mean total number of oral side effects was higher in the one-dose group (Table 10).

Table 10. Number of doses and the side effects of Pfizer-BioNTech COVID-19 vaccine among healthcare workers in the Czech Republic, January-February 2021.

\begin{tabular}{|c|c|c|c|}
\hline & One Dose & Two Doses & Significance $^{1}$ \\
\hline Injection site pain & $44(88 \%)$ & $690(90 \%)$ & 0.657 \\
\hline Injection site swelling & $12(24 \%)$ & $197(25.7 \%)$ & 0.791 \\
\hline Injection site redness & $4(8 \%)$ & $183(23.9 \%)$ & 0.010 \\
\hline Fatigue & $30(60 \%)$ & $477(62.2 \%)$ & 0.757 \\
\hline Headache & $21(42 \%)$ & $353(46 \%)$ & 0.580 \\
\hline Nausea & $6(12 \%)$ & $101(13.2 \%)$ & 0.812 \\
\hline Feeling unwell & $16(32 \%)$ & $173(22.6 \%)$ & 0.125 \\
\hline Muscle pain & $18(36 \%)$ & $286(37.3 \%)$ & 0.855 \\
\hline Chills & $17(34 \%)$ & $260(33.9 \%)$ & 0.988 \\
\hline Joint pain & $17(34 \%)$ & $210(27.4 \%)$ & 0.311 \\
\hline Fever & $11(22 \%)$ & $168(21.9 \%)$ & 0.987 \\
\hline Lymphadenopathy & $8(16 \%)$ & $124(16.2 \%)$ & 0.975 \\
\hline Number of General SE & $4.08 \pm 2.52$ & $4.20 \pm 2.63$ & 0.752 \\
\hline Ulcers & $1(14.3 \%)$ & $15(13.9 \%)$ & 0.977 \\
\hline Vesicles & $0(0 \%)$ & $4(3.7 \%)$ & 0.604 \\
\hline Blisters & $2(28.6 \%)$ & $39(36.1 \%)$ & 0.687 \\
\hline White/red plaque & $1(14.3 \%)$ & $11(10.2 \%)$ & 0.731 \\
\hline Halitosis & $4(57.1 \%)$ & $25(23.1 \%)$ & 0.045 \\
\hline Bleeding gingiva & $2(28.6 \%)$ & $11(10.2 \%)$ & 0.137 \\
\hline Burning gingiva & $0(0 \%)$ & $10(9.3 \%)$ & 0.399 \\
\hline Swollen lips & $0(0 \%)$ & $4(3.7 \%)$ & 0.604 \\
\hline Angular cheilitis & $0(0 \%)$ & $5(4.6 \%)$ & 0.561 \\
\hline Xerostomia & $0(0 \%)$ & $3(2.8 \%)$ & 0.655 \\
\hline Taste disturbance & $0(0 \%)$ & $4(3.7 \%)$ & 0.604 \\
\hline Tongue tingling & $0(0 \%)$ & $5(4.6 \%)$ & 0.561 \\
\hline Number of Oral SEs & $1.43 \pm 1.13$ & $1.31 \pm 0.56$ & 0.610 \\
\hline Rash & $2(100 \%)$ & $26(60.5 \%)$ & 0.260 \\
\hline Urticaria & $0(0 \%)$ & $10(23.3 \%)$ & 0.439 \\
\hline Other skin-related SEs & $0(0 \%)$ & $9(20.9 \%)$ & 0.469 \\
\hline Number of skin-related SEs & $1 \pm 0$ & $1.04 \pm 0.202$ & 0.774 \\
\hline
\end{tabular}

${ }^{1}$ Chi-squared test and ANOVA were used with a significance level of $<0.05$. 


\subsubsection{Oral and General Side Effects of COVID-19 Vaccine}

The emergence of oral side effects was significantly associated with some general side effects, e.g., headache $\left(\chi^{2}=13.18 ; p<0.001\right)$, nausea $\left(\chi^{2}=10.36 ; p=0.001\right)$, muscle pain $\left(\chi^{2}=4.56 ; p=0.033\right)$, fever $\left(\chi^{2}=4.86 ; p=0.027\right)$, and lymphadenopathy $\left(\chi^{2}=9.78\right.$; $p=0.002)$. In addition to the association between the total number of general side effects, their duration, and the emergence of oral side effects, blisters were significantly lower among the participants receiving thyroid hormone replacements $\left(\chi^{2}=4.05 ; p=0.044\right)$. In contrast, angular cheilitis was significantly more prevalent among the participants receiving thyroid hormone replacements $\left(\chi^{2}=7.2 ; p=0.007\right)$.

\section{Discussion}

The first evidence to evaluate the efficacy of the Pfizer-BioNTech COVID-19 vaccine was obtained from a randomized controlled trial (RCT) which recruited 43,000 volunteers with a median age of 52 years old. The early results of this RCT showed that the vaccine's efficacy was around 95\%, with several adverse reactions that occurred in the few days following the vaccine shot [19]. The vaccine's side effects could be categorized as either local or systemic reactions, and their severity varied from mild to moderate [31].

The present study reported a statistically significant difference in the prevalence of injection site pain $(p=0.001)$, fatigue $(p=0.026)$, headache $(p=0.003)$, muscle pain $(p=0.023)$, and feeling unwell $(p=0.038)$ between the $\leq 43$-year-old group and the $>43$ year-old group, where the younger adults were more frequently affected. These findings are consistent with those reported by the Food and Drug Administration (FDA): injection site pain was more prevalent in the $\leq 55$-year-old group than the $>55$-year-old group $(80.56 \%$ vs. $68.75 \%)$; fatigue was more prevalent in the younger group ( $53.13 \%$ vs. $42 \%)$, headache was also more prevalent in the younger group ( $46.57 \%$ vs. $31.8 \%)$; and muscle pain was more prevalent in the younger group (28.94\% vs. $21.03 \%)$ [19].

However, differences between the age groups in terms of fever, chills and joint pain were not statistically significant in our sample: the $\leq 43$-year-old group was more affected by fever $(9.47 \%$ vs. $5.98 \%)$, chills ( $36.8 \%$ vs. $30.9 \%$ ) and joint pain ( $28.6 \%$ vs. $26.9 \%)$ than the $>43$-year-old group. These trends were similar to the FDA's report, where fever was more prevalent among young adults than old adults $(24.3 \%$ vs. $19.1 \%)$, and the same pattern was recorded for chills $(24.11 \%$ vs. $14.15 \%)$ and joint pain $(16.18 \%$ vs. $13.52 \%)$. In contrast to the manufacturer's data, injection site swelling ( $26 \%$ vs. $25.2 \%$ ) and injection site redness ( $25.5 \%$ vs. $20.4 \%)$ were more frequent in the younger age group of our sample. According to the FDA's report, injection site swelling was slightly less frequent among the younger adults $(6.02 \%$ vs. $7.51 \%)$. Injection site redness was also slightly less frequent among the younger adults ( $5.37 \%$ vs. $5.92 \%)$.

The overall frequency of systemic reactions including fever, fatigue, headache, chills, vomiting, diarrhea, muscle pain and joint pain was significantly higher among the younger adults than the older adults, according to the FDA's report (82.8\% vs. $70.6 \%)$. The same pattern was reported for local reactions, including injection site pain, swelling, and redness, where $88.7 \%$ of younger adults were affected compared to $79.7 \%$ of the older. This pattern was identified in our sample; the mean number of side effects $(4.50 \pm 2.596$ vs. $3.87 \pm 2.599)$ and the overall frequency of affected participants ( $94.8 \%$ vs. $91.5 \%)$ were significantly higher in the younger than the older.

The overall frequencies of injection site pain $(89.8 \%$ vs. $75.35 \%)$, injection site swelling ( $25.6 \%$ vs. $6.44 \%$ ), and injection site swelling ( $23 \%$ vs. $5.5 \%)$ were significantly higher among the Czech healthcare workers than the volunteers of the Pfizer-BioNTech trial [19]. In contrast, the overall frequency of headache was quite consistent between the Czech sample and the FDA's report ( $45.6 \%$ vs. $40.06 \%$, respectively).

On comparing the first dose and the second dose of the vaccine, the FDA's report revealed that the frequency of local side effects was slightly higher after the second dose compared to the first dose. The same trend was more significant in the case of systemic 
side effects [19]. The Czech data confirmed this trend in all the reported side effects except for injection site redness, which was more frequent among the people with one dose only.

Injection site pain as a subjectively reported symptom has a number of confounders that are worth being considered for future research on vaccines' side effects, including injection technique, vaccine temperature, and injection velocity. These confounders are difficult to be standardized and will significantly impact one's experience [32]. Moreover, injection in a relaxed muscle leads to less pain compared to a tensed one; therefore, it is recommended to lower the patient's arm which will be injected. Vaccines in situ are preserved in very low temperature, including the BNT162b2 vaccine which requires $-70^{\circ} \mathrm{C}$, and if injected without optimal warming up, this may increase the probability of postvaccination pain of the injection site [33]. Additionally, muscle mass might play a role in pain perception following the injection. The healthcare workers involved in the vaccination process are highly recommended to receive appropriate training on optimal injection techniques to reduce inequalities in patients' experience of pain after vaccination [34].

The allergic population that used antihistamine drugs were the most susceptible group for experiencing side effects, because they were significantly affected by injection site redness $\left(\chi^{2}=6.27 ; p=0.012\right)$, headache $\left(\chi^{2}=7.5 ; p=0.006\right)$, nausea $\left(\chi^{2}=4.97 ; p=0.026\right)$, fever $\left(\chi^{2}=6.62 ; p=0.01\right)$, chills $\left(\chi^{2}=6.1 ; p=0.014\right)$, and lymphadenopathy $\left(\chi^{2}=5.54\right.$; $p=0.019)$. The Centers for Disease Control and Prevention (CDC) had stated, within its interim guidelines for COVID-19 vaccine rollout, that people with a history of any immediate allergic reaction to other vaccines or injectable therapies should be vaccinated with high precaution. People with a history of severe allergic reactions such as anaphylaxis after a previous dose or to a component of the vaccine such as polyethylene glycol (PEG) are prohibited from receiving the vaccine at this stage [31]. Although people with allergies to oral medications, food, pets, insects, venom, latex, and other environmental insults and family histories are recommended to proceed with receiving the vaccine normally, it is worth noting that antihistamine consumption increases considerably in spring in Europe; therefore, special attention should be given to the prescription of these drugs during this season in the context of vaccination. This result will be further explored in our upcoming study phase.

Lymphadenopathy of the arm and neck was among the unsolicited side effects in the FDA's report with 64 cases; however, it should have been a predictable side effect due to it being common with other vaccines such as the human papillomavirus vaccine and influenza vaccine [35-37] Therefore, in this study, lymphadenopathy was among the general side effects of the COVID-19 vaccine and its overall prevalence was $16.2 \%$, with a higher frequency among females compared to males (16.8\% vs. $10.6 \%)$, young adults compared to old adults (17.3\% vs. $15.1 \%)$, and people with allergies $(21.4 \%$ vs. $14.5 \%)$, asthma ( $17.6 \%$ vs. $14.1 \%)$, bowel disease ( $25 \%$ vs. $14.3 \%)$, cardiac disease $(25 \%$ vs. $14.2 \%)$, COPD ( $20 \%$ vs. $14.8 \%)$, DM type- $2(19 \%$ vs. $14.5 \%)$, and neurologic disease ( $30 \%$ vs. $14.2 \%$ ). The majority of participants with lymphadenopathy reported that its duration was either one day $(18.9 \%)$, three days $(43.9 \%)$, or five days $(18.2 \%)$. This finding is slightly in agreement with the FDA's report, where lymphadenopathy emerged 2-4 days post-vaccination and lasted for approximately 10 days.

The median interval between the first dose and the second dose was 21 days, which is in compliance with the recommended interval of the Czech ministry of health (MOH) [38]. The median patency period between the recovery date and the first vaccine dose was 65 days, which fulfills the recommendation of the $\mathrm{Czech} \mathrm{MOH}$ for a patency period of seven days between the positive test and the vaccination [39].

The reported NCDs in our sample were generally less frequent than what is reported for the general Czech population. This difference was predictable for this special subset of the population, because medical fitness is a prerequisite for pursuing healthcare professions. Unfortunately, the data on diseases prevalence in the Czech Republic are not stratified by profession or employment sector; therefore, there is no reference prevalence for Czech healthcare workers. Diabetes Mellitus type- 2 had prevalence in the Czech Republic around 
7.4\% (2017); however, in our sample, its prevalence was considerably lower 2.63\% [40,41]. Cardiac disease and chronic hypertension had prevalence around $4.3 \%$ and $23.7 \%$, respectively (2019), which were two-fold higher than the prevalence values of our sample, which were $1.83 \%$ and $11.44 \%$, respectively [42,43]. In contrast, asthma had a prevalence in the Czech Republic 4.5\% (2018), while in our sample it was 6.75\% [44]. Thyroid disease had a prevalence in the Czech Republic in $7.5 \%$ (2015) which was similar to our sample $(7.89 \%)[45]$.

\subsection{Strengths and Limitations}

The findings of this study should be interpreted cautiously regarding the association of side effects with the second dose of the vaccine, because we did not ask whether the side effect occurred after the first dose or the second dose. The external validity of this study is limited because the sample was not equally distributed across gender or profession. Another methodological limitation is due to the survey-based technique that may lead to self-selection bias, when perhaps only the highly motivated participants filled in the questionnaire. The self-reporting nature of the collected data compromises its objectivity when it comes to clinical evaluation and standardization. This methodological confounding had been controlled to some degree because all the study's participants were healthcare workers who have a high level of health literacy and medical expertise, so the outcomes were supposed to be accurately reported. To the best of our knowledge, this was the first independent study dealing with the BNT162b2 vaccine side effects, and the first designed study evaluating the side effects among a European population.

\subsection{Study Implications}

1. Further independent (non-sponsored) epidemiological studies for COVID-19 vaccine side effects should be carried out by academic institutions in the upcoming months to increase public confidence in the vaccines' safety and accelerate its uptake process.

2. The upcoming studies will benefit from comparing data of different vaccines from other manufacturers.

3. The upcoming studies of vaccine side effects should distinguish between the side effects that emerged after the first dose, the second dose, and both doses.

4. Healthcare workers and healthcare students are among the ideal population groups to participate in this type of studies due to their high level of health literacy and scientific motivation.

5. The potential association between antihistamine drugs and the vaccine side effects' frequency should be further explored.

\section{Conclusions}

The most common side effects of the Pfizer-BioNTech COVID-19 vaccine among Czech healthcare workers were injection site pain, fatigue, headache, muscle pain, chills, and joint pain. They were highly consistent with the data reported by the manufacturer in terms of their association with the younger age group and the second dose. The overall prevalence of some local and systemic side effects was higher than the manufacturer's report; this could be attributed to the special type of population enrolled in this study. Antihistamines were the most common drugs associated with side effect emergence, which might require special attention in the following months. The oral side effects were significantly associated with headache, nausea, muscle pain, fever, and lymphadenopathy. Further independent studies on vaccine safety are strongly required to strengthen the public confidence in the vaccine, and to provide a better understanding of the potential risk factors of vaccine side effects.

Supplementary Materials: The following are available online at https://www.mdpi.com/article/10 $.3390 /$ jcm10071428/s1, Table S1: OSECV Instrument (in Czech). 
Author Contributions: Conceptualization, A.R. and M.K. (Miloslav Klugar); methodology, A.R. and S.A.; validation, S.A., J.K. and M.K. (Miloslav Klugar); formal analysis, A.R. and M.K. (Miloslav Klugar); investigation, A.P. and M.K. (Michal Koščík); data curation, A.P. and M.K. (Michal Koščík); writing-original draft preparation, A.R.; writing-review and editing, A.P., S.A., J.K. and M.K. (Michal Koščík); supervision, M.K. (Miloslav Klugar); project administration, A.R.; funding acquisition, M.K. All authors have read and agreed to the published version of the manuscript.

Funding: This study was funded by Masaryk University, grant numbers MUNI/IGA/1543/2020 and MUNI/A/1608/2020. The work of A.R., A.P., J.K., and M.K. (Miloslav Klugar) was supported by the INTER-EXCELLENCE grant number LTC20031-“'Towards an International Network for Evidence-based Research in Clinical Health Research in the Czech Republic". The work of M.K. (Michal Koščík) was supported by the European Regional Development Fund-Project CZECRIN_4 PACIENTY (No. CZ.02.1.01/0.0/0.0/16_013/0001826) and the project Large Research infrastructure CZECRIN (LM2018128).

Institutional Review Board Statement: The study was conducted according to the guidelines of the Declaration of Helsinki and approved by the Ethics Committee of the Faculty of Medicine, Masaryk University Ref. 2/2021 on 20 January 2021.

Informed Consent Statement: Informed consent was obtained from all participants involved in the study.

Data Availability Statement: The data that support the findings of this study are available from the corresponding author upon reasonable request.

Acknowledgments: This work is dedicated to the more than two million worldwide fatalities and their families who have fallen victim to COVID-19. The authors thank Lydie Izakovičová Hollá and Lenka Součková for their help with dissemination of questionnaires among the potential participants of the study.

Conflicts of Interest: The authors declare no conflict of interest.

\section{References}

1. Butler, R.; MacDonald, N.E.; Eskola, J.; Liang, X.; Chaudhuri, M.; Dube, E.; Gellin, B.; Goldstein, S.; Larson, H.; Manzo, M.L.; et al. Diagnosing the determinants of vaccine hesitancy in specific subgroups: The Guide to Tailoring Immunization Programmes (TIP). Vaccine 2015, 33, 4176-4179. [CrossRef]

2. Harrison, E.A.; Wu, J.W. Vaccine confidence in the time of COVID-19. Eur. J. Epidemiol. 2020, 35, 325-330. [CrossRef]

3. Dror, A.A.; Eisenbach, N.; Taiber, S.; Morozov, N.G.; Mizrachi, M.; Zigron, A.; Srouji, S.; Sela, E. Vaccine hesitancy: The next challenge in the fight against COVID-19. Eur. J. Epidemiol. 2020, 35, 775-779. [CrossRef] [PubMed]

4. Luyten, J.; Bruyneel, L.; van Hoek, A.J. Assessing vaccine hesitancy in the UK population using a generalized vaccine hesitancy survey instrument. Vaccine 2019, 37, 2494-2501. [CrossRef] [PubMed]

5. Szmyd, B.; Bartoszek, A.; Karuga, F.F.; Staniecka, K.; Błaszczyk, M.; Radek, M. Medical Students and SARS-CoV-2 Vaccination: Attitude and Behaviors. Vaccines 2021, 9, 128. [CrossRef]

6. Szmyd, B.; Karuga, F.F.; Bartoszek, A.; Staniecka, K.; Siwecka, N.; Bartoszek, A.; Błaszczyk, M.; Radek, M. Attitude and Behaviors towards SARS-CoV-2 Vaccination among Healthcare Workers: A Cross-Sectional Study from Poland. Vaccines 2021, 9, 218. [CrossRef]

7. Jarrett, C.; Wilson, R.; O’Leary, M.; Eckersberger, E.; Larson, H.J.; Eskola, J.; Liang, X.; Chaudhuri, M.; Dube, E.; Gellin, B.; et al. Strategies for addressing vaccine hesitancy-A systematic review. Vaccine 2015, 33, 4180-4190. [CrossRef]

8. Attia, S.; Howaldt, H.-P. Impact of COVID-19 on the Dental Community: Part I before Vaccine (BV). J. Clin. Med. 2021, 10, 288. [CrossRef]

9. Sawires, L. Effects of the Influenza Vaccine on the Oral Cavity. 2018. Available online: https://stars.library.ucf.edu/cgi/ viewcontent.cgi? article $=1306 \&$ context=honorstheses (accessed on 16 December 2020).

10. Gonçalves, A.K.; Cobucci, R.N.; Rodrigues, H.M.; De Melo, A.G.; Giraldo, P.C. Safety, tolerability and side effects of human papillomavirus vaccines: A systematic quantitative review. Braz. J. Infect. Dis. 2014, 18, 651-659. [CrossRef]

11. Riad, A.; Klugar, M.; Krsek, M. COVID-19 Related Oral Manifestations, Early Disease Features? Oral Dis. 2020. [CrossRef]

12. Riad, A.; Kassem, I.; Issa, J.; Badrah, M.; Klugar, M. Angular cheilitis of COVID-19 patients: A case-series and literature review. Oral Dis. 2020. [CrossRef]

13. Riad, A.; Kassem, I.; Stanek, J.; Badrah, M.; Klugarova, J.; Klugar, M. Aphthous Stomatitis in COVID-19 Patients: Case-series and Literature Review. Dermatol. Ther. 2021, 34, e14735. [CrossRef] [PubMed]

14. Riad, A.; Kassem, I.; Hockova, B.; Badrah, M.; Klugar, M. Tongue ulcers associated with SARS-CoV-2 infection: A case series. Oral Dis. 2020. [CrossRef] 
15. Hocková, B.; Riad, A.; Valky, J.; Šulajová, Z.; Stebel, A.; Slávik, R.; Bečková, Z.; Pokorná, A.; Klugarová, J.; Klugar, M. Oral Complications of ICU Patients with COVID-19: Case-Series and Review of Two Hundred Ten Cases. J. Clin. Med. 2021, 10, 581. [CrossRef]

16. Riad, A.; Gad, A.; Hockova, B.; Klugar, M. Oral candidiasis in non-severe COVID-19 patients: Call for antibiotic stewardship. Oral Surg. 2020. [CrossRef] [PubMed]

17. Riad, A.; Kassem, I.; Badrah, M.; Klugar, M. The manifestation of oral mucositis in COVID-19 patients: A case-series. Dermatol. Ther. 2020, 33. [CrossRef] [PubMed]

18. Maspero, C.; Abate, A.; Cavagnetto, D.; El Morsi, M.; Fama, A.; Farronato, M. Available Technologies, Applications and Benefits of Teleorthodontics. A Literature Review and Possible Applications during the COVID-19 Pandemic. J. Clin. Med. 2020, 9, 1891. [CrossRef]

19. Centres for Diseases Control and Prevention (CDC). Reactions and Adverse Events of the Pfizer-BioNTech COVID-19 Vaccine. Available online: https:/ / www.cdc.gov/vaccines/covid-19/info-by-product/pfizer/reactogenicity.html (accessed on 7 March 2021).

20. Masaryk University. Oral Side Effects of COVID-19 Vaccine (OSECV). 2021. Available online: https://clinicaltrials.gov/ct2 / show / NCT04706156 (accessed on 24 February 2021).

21. Von Elm, E.; Altman, D.G.; Egger, M.; Pocock, S.J.; Gøtzsche, P.C.; Vandenbroucke, J.P. The Strengthening the Reporting of Observational Studies in Epidemiology (STROBE) Statement: Guidelines for reporting observational studies. Ann. Int. Med. 2007, 147, 573-577. [CrossRef]

22. Ústav Zdravotnických Informací a Statistiky České Republiky (ÚZIS ČR). Systém Hlášení Nežádoucích Událostí (SHNU). 2021. Available online: https:/ / shnu.uzis.cz/ (accessed on 8 March 2021).

23. CZECRIN. Czech Clinical Research Infrastructure Network. Available online: https://czecrin.cz/en/home/ (accessed on 2 March 2021).

24. Proton Technologies AG. General Data Protection Regulation (GDPR) Compliance Guidelines. HORIZON 2020-Project REP791727-1. Available online: https:/ /gdpr.eu/ (accessed on 1 May 2020).

25. Ministry of Interior-Czech Republic. Who Will Be Vaccinated First? Covid Portál. Available online: https://covid.gov.cz/en/ situations / register-vaccination/who-will-be-vaccinated-first (accessed on 2 March 2021).

26. Tarakji, B.; Umair, A.; Alakeel, R.; Ashok, N.; Azzeghaibi, S.; Darwish, S.; Mahmoud, R.; Elkhatat, E. Hepatitis B vaccination and associated oral manifestations: A non-systematic review of literature and case reports. Ann. Med. Health Sci. Res. $2014,4,829$. [CrossRef]

27. McHugh, M.L. Interrater reliability: The kappa statistic. Biochem. Med. 2012, 22, 276-282. [CrossRef]

28. OECD. Health at a Glance 2019; OECD: Paris, France, 2019; ISBN 9789264382084.

29. Národní Pedagogický Institut České Republiky. Odborní Pracovníci v Oblasti Zdravotnictví Kromě Všeobecných Sester bez Specializace. Available online: https:/ / www.infoabsolvent.cz/Temata/ClanekAbsolventi/8-8-17 (accessed on 8 March 2021).

30. Institute of Health Information and Statistics of the Czech Republic (UZIS). Health Yearbook of the Czech Republic 2017. 2018. Available online: https: / / www.uzis.cz/index-en.php?pg=record\&id=8166 (accessed on 3 March 2021).

31. Oliver, S.E.; Gargano, J.W.; Marin, M.; Wallace, M.; Curran, K.G.; Chamberland, M.; McClung, N.; Campos-Outcalt, D.; Morgan, R.L.; Mbaeyi, S.; et al. The Advisory Committee on Immunization Practices' Interim Recommendation for Use of Pfizer-BioNTech COVID-19 Vaccine-United States, December 2020. Morb. Mortal. Wkly. Rep. 2020, 69, 1922-1924. [CrossRef]

32. Ozdemir, L.; Pnarc, E.; Akay, B.N.; Akyol, A. Effect of Methylprednisolone Injection Speed on the Perception of Intramuscular Injection Pain. Pain Manag. Nurs. 2013, 14, 3-10. [CrossRef]

33. Centers for Disease Control and Prevention (CDC). Interim Clinical Considerations for Use of COVID-19 Vaccines. Available online: https://www.cdc.gov/vaccines / covid-19/info-by-product/clinical-considerations.html?CDC_AA_refVal=https\%3A\% 2F\%2Fwww.cdc.gov\%2Fvaccines\%2Fcovid-19\%2Finfo-by-product $\% 2$ Fpfizer\%2Fclinical-considerations.html (accessed on 7 March 2021).

34. Training and Education Resources I COVID-19 Vaccination I CDC. Available online: https://www.cdc.gov/vaccines / covid-19 /training-education-resources.html (accessed on 8 March 2021).

35. Pereira, M.P.; Flores, P.; Neto, A.S. Neck and supraclavicular lymphadenopathy secondary to 9-valent human papillomavirus vaccination. BMJ Case Rep. 2019, 12, e231582. [CrossRef]

36. Shirone, N.; Shinkai, T.; Yamane, T.; Uto, F.; Yoshimura, H.; Tamai, H.; Imai, T.; Inoue, M.; Kitano, S.; Kichikawa, K.; et al. Axillary lymph node accumulation on FDG-PET/CT after influenza vaccination. Ann. Nucl. Med. 2012, 26, 248-252. [CrossRef]

37. Studdiford, J.; Lamb, K.; Horvath, K.; Altshuler, M.; Stonehouse, A. Development of Unilateral Cervical and Supraclavicular Lymphadenopathy After Human Papilloma Virus Vaccination. Pharmacotherapy 2008, 28, 1194-1197. [CrossRef]

38. Ministry of Interior-Czech Republic. Information about Available Vaccines. Covid Portál. 2021. Available online: https: / / covid.gov.cz/en/situations/information-about-vaccine/information-about-available-vaccines (accessed on 3 March 2021).

39. Ministry of Interior-Czech Republic. Specific Situations during Vaccination. Covid Portál. 2021. Available online: https: // covid.gov.cz/en/situations/information-about-vaccine/specific-situations-during-vaccination (accessed on 3 March 2021).

40. ÚZIS-ČR. Stručný Přehled Činnosti Oboru Diabetologie a Endokrinologie 2017; Ústav Zdravotnických Informací a Statistiky ČR: Prague, Czech Republic, 2007. 
41. Klugar, M.; Klugarová, J.; Pokorná, A.; Benešová, K.; Jarkovský, J.; Dolanová, D.; Mužík, J.; Líčeník, R.; Prázný, M.; Búřilová, P.; et al. Use of epidemiological analyses in Clinical Practice Guideline development focused on the diabetic patients treated with insulin. Int. J. Evid. Based. Healthc. 2019, 17, S48-S52. [CrossRef]

42. Klugar, M.; Hunčovský, M.; Pokorná, A.; Dolanová, D.; Benešová, K.; Jarkovský, J.; Mužík, J.; Líčeník, R.; Nečas, T.; Búřilová, P.; et al. Epidemiological analyses for preparation of Clinical Practice Guidelines related to acute coronary syndromes in the Czech Republic. Int. J. Evid. Based. Healthc. 2019, 17, S43-S47. [CrossRef]

43. ÚZIS-ČR. Zdravotnická ročenka ČR 2018; Ústav Zdravotnických Informací a Statistiky ČR: Prague, Czech Republic, 2018.

44. ÚZIS-ČR. Stručný Přehled Činnosti Oboru Pneumologie a Ftizeologie za Období 2007-2019; Ústav Zdravotnických Informací a Statistiky ČR: Prague, Czech Republic, 2007.

45. Bílek, R.; Horakova, L.; Gos, R.; Zamrazil, V. Thyroid disease in the Czech Republic: The EUthyroid project and the evaluation of the General Health Insurance Company epidemiological data for the period of 2012-2015. Vnitř. Lék. 2017, 63, 548-554. 